\title{
Osteoplastic Reconstruction of Post-enucleatic Microorbitalism
}

\author{
Ji Young Yun, Seok Ju Kang, Jin Woo Kim, Young Hwan Kim, Hook Sun \\ Department of Plastic and Reconstructive Surgery, Inje University Busan Paik Hospital, Inje University College of Medicine, Busan, Korea
}

\begin{abstract}
Background Patients who have undergone enucleation during infancy due to retinoblastoma can develop microorbitalism due to the decreased growth stimulation from the eyeball and the surrounding soft tissues. Anatomically, the orbit consist of parts of the frontal bone superiorly, the maxilla inferiorly, the ethmoid bone medially, and the zygoma laterally. Considering the possibility of surgically expanding the orbit using tripod osteotomy, in this study we conducted tripod osteotomy on adult patients with microorbitalism of retinoblastoma.

Methods Tripod osteotomy was conducted to expand the orbital volume in adult patients with microorbitalism due to enucleation in infancy for retinoblastoma. The orbital volume was measured using the Aquarius Workstation ver. 4.3.6 and the orbit width was measured with preoperative and postoperative 3-dimensional facial bone computed tomography (CT) imaging. Preoperative and postoperative photographs were used to visualize the difference produced by the surgery.

Results The orbital volume of the affected side was $10.3 \mathrm{~cm}^{3}$ before and $12.5 \mathrm{~cm}^{3}$ after the surgery, showing an average increase in volume of $2.2 \mathrm{~cm}^{3}(21.4 \%)$. The increase in the obital width was confirmed by the preoperative and postoperative 3-dimensional facial CT images and aesthetic improvement was observed by the preoperative and postoperative photographs. Conclusions Tripod osteotomy, which realigns the orbital bone, zygoma, and maxilla, is used to correct posttraumatic malunion as well as non-traumatic congenital abnormalities such as that seen in facial cleft. We applied this procedure in microorbitalism secondary to enucleation for retinoblastoma to allow orbital expansion and correct asymmetry.
\end{abstract}

\section{Keywords Orbit / Osteotomy / Retinoblastoma}

Correspondence: Hook Sun Department of Plastic and

Reconstructive Surgery, Inje University

Busan Paik Hospital, Inje University

College of Medicine, 75 Bokji-ro,

Busanjin-gu, Busan 614-735, Korea

Tel: +82-51-890-6236

Fax: +82-51-894-7976

E-mail: sun443@naver.com

Received: 29 Feb 2012 • Revised: 9 Jun 2012 • Accepted: 9 Jun 2012

pISSN: 2234-6163 • elSSN: 2234-6171 • http://dx.doi.org/10.5999/aps.2012.39.4.333・Arch Plast Surg 2012;39:333-337

\section{INTRODUCTION}

Microorbitalism is a rare abnormality of the facial bone that arises as a result of deficient growth stimulation from the eyeball and the surrounding soft tissue. Causes of microorbitalism include congenital causes such as anophthalmia or microphthalmia as well as enucleation related to pathologies or trauma, or radiotherapy in infancy [1]. Microorbitalism in such patients can be corrected non-surgically by using expanders or surgically by realigning the orbital wall by osteotomy and relocation [2]. The orbit is anatomically a three-dimensional cone-shaped structure consisting of the parts of the frontal bone superiorly, the maxilla inferiorly, the ethmoid bone medially, and the zygoma laterally. The structure of the bones which make up the orbit

Copyright $(\odot) 2012$ The Korean Society of Plastic and Reconstructive Surgeons

This is an Open Access article distributed under the terms of the Creative Commons Attribution Non-Commercial License (http://creativecommons.org/

licenses/by-nc/3.0/) which permits unrestricted non-commercial use, distribution, and reproduction in any medium, provided the original work is properly cited.

www.e-aps.org 
can be altered surgically to correct microorbitalism. Previously, osteotomy of the lateral orbital wall was performed to correct microorbitalism. However, this method has limitations because it involves removal of a part of the zygoma, which forms the orbit.

We have previously reported that the application of tripod osteotomy can be extended to include correction of acquired malunion following simple facial bone fractures as well as correction of various congenital deformities that are associated with delayed development and malformations of the zygoma-orbitmaxilla complex $[3,4]$. Based on the fact that tripod osteotomy can be used to increase the volume of the orbit, we have conducted tripod osteotomy on adult patients with microorbitalism secondary to enucleation for retinoblastoma during infancy. In this study we report on the satisfactory change in orbital volume resulting from surgery.

\section{METHODS}

\section{Subjects}

The surgical procedure was carried out in 5 individuals who were admitted to our hospital between January 2006 and May 2011 with microorbitalism secondary to enucleation for retinoblastoma in childhood. Of the 5 subjects, 4 were male and 1 was female. The age of the patients ranged between 18 and 20 years old, with an average age of 18.6 years. All 5 subjects had received enucleation and radiotherapy before the age of three and had no prior treatment for microorbitalism.

\section{Surgical methods}

Under general anesthesia, a bicoronal approach, subciliary approach, and intraoral incision were used to expose the zygoma-

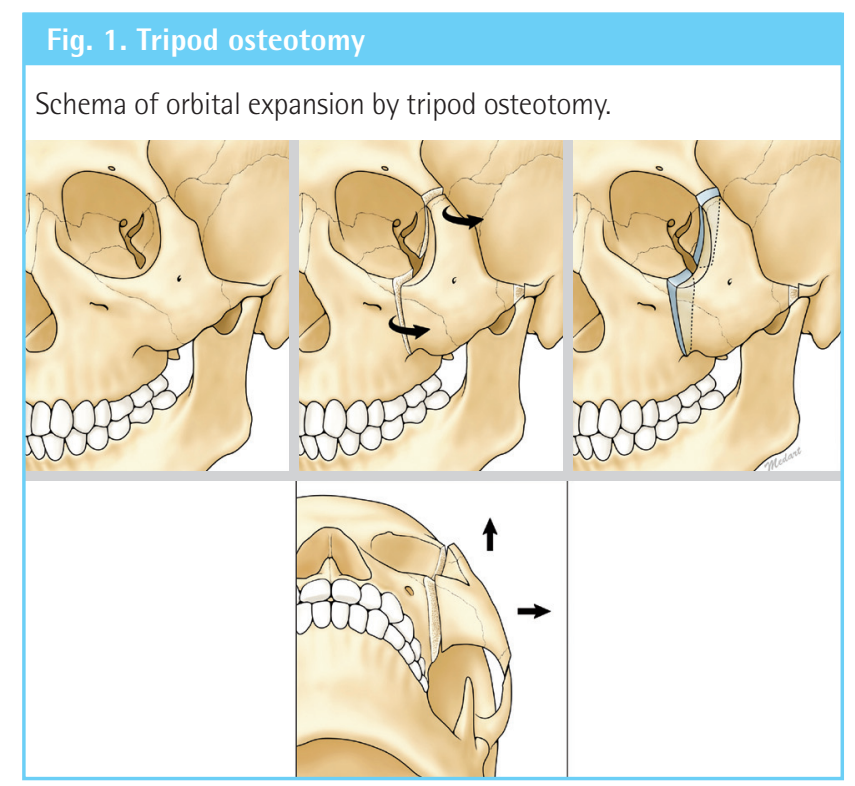

orbit-maxilla complex and the orbital floor to finally expose the zygomatico-frontal suture, zygomatic arch, and the zygoma body. Tripod osteotomy was conducted at the exposed zygomaticofrontal suture, zygomatic arch, and the zygomaticomaxilla suture, and then the zygoma-orbit-maxilla complex was relocated anterolaterally and inferiorly. The masticatory muscle and the temporal muscle were partially detached and were relocated at an anatomically symmetric position to minimize the displacement due to muscle contraction. To reduce bleeding and nerve damage during osteotomy in the zygomaticomaxilla suture area, a new osteotomy line passing through the lateral side of the infraorbital foramen and the infraorbital margin was made.

In these cases, the zygomatic arch was osteotomed obliquely to maximize bone contact, so that we minimize any harmful effects to the temporomandibular joint. A bone graft was carried out following osteotomy to fill the bone gap and bone cement was used to contour the surface (Fig. 1).

\section{Orbital volume measurement and follow-up studies}

The preoperative and postoperative orbital volume was measured using the Aquarius Workstation ver. 4.3.6 (TeraRecon Inc., San Mateo, CA, USA). The field was selected in the coro-

\section{Fig. 2. Measurement of orbital volume by Aquarius Work- station ver. 4.3.6.}

The orbital volume is displayed in four different views: transaxial, coronal, sagittal, and a three-dimensional reconstruction view. Every view was reformatted from 1-mm thickness slices. Drawing the contour of the bony orbit in each slice was conducted in the coronal plane. The above right is a three-dimensional reconstruction of the orbital volume.

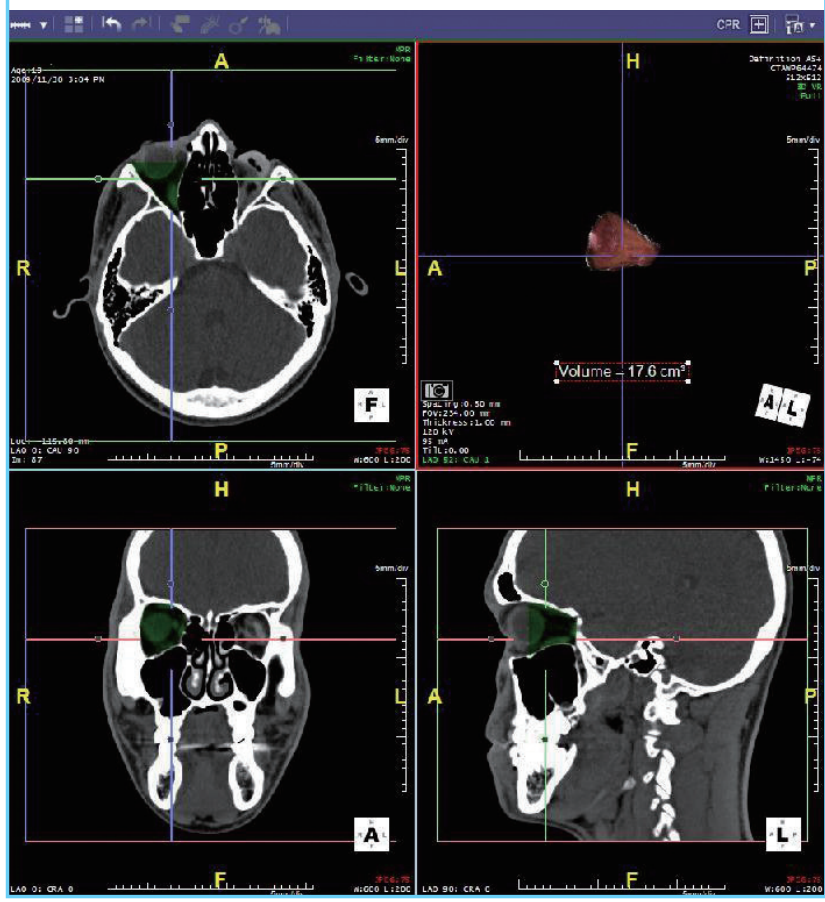


nal plane as the anatomical position of the orbital floor and the zygoma could be best seen with 3-dimensional facial bone computed tomography (CT). The beginning of the orbit was set as the slice where the whole circular structure of the orbit could be visualized. The end of the orbit was set as the slice just before the disappearance of the circular structure of the orbit behind the sphenoid bone inside the eyeball. The borders of the orbit were defined at every $1 \mathrm{~mm}$ for each slice. To minimize measurement error during the illustration of the orbital border, the measurements were made three times by one person and the average value was used (Fig. 2).

To compare the postoperative outcome and to follow-up, 3-dimensional facial bone CT and photography was taken preoperatively and at 6 months postoperatively. The widest width

\section{Fig. 3. Preoperative and postoperative $3-D$ facial bone CT} images

Preoperative and postoperative 3-dimensional facial bone computed tomography (CT) images of case $1(\mathrm{~A}, \mathrm{~B})$. The preoperative and postoperative 3-dimensional facial bone $\mathrm{CT}$ images show anatomical expansion in the orbital volume.
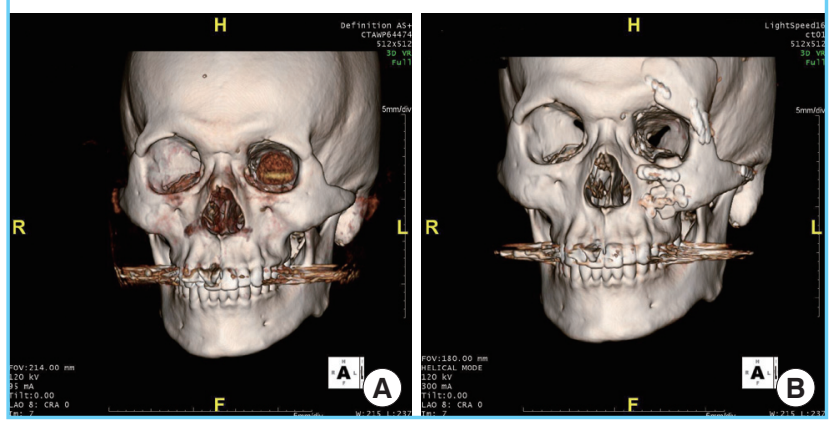

at the start of the orbit in the coronal view of the 3-dimensional facial bone CT was compared between pre- and postoperative CT images and the changes in malar height were observed from the photographs taken.

\section{RESULTS}

As measured by the Aquarius Workstation ver. 4.3.6 the average preoperative eyeball volume of the unaffected side was 14.1 $\mathrm{cm}^{3}$, while that of the affected side was $10.3 \mathrm{~cm}^{3}$. The average postoperative eyeball volume of the affected side was measured to be $12.5 \mathrm{~cm}^{3}$, showing an average increase of $2.2 \mathrm{~cm}^{3}(21.4 \%)$. Comparing the 3-dimensional facial bone CT, the orbital width was found to have increased from an average of $29 \mathrm{~mm}$ to an average of $32.8 \mathrm{~mm}$ (Table 1 ).

Radiological comparison with 3-dimensional facial bone CT taken at 6 months postoperation showed an increase in the orbital space and the patients showed aesthetic improvements in midface asymmetry with an increase in malar height (Figs. 3, 4).

\section{DISCUSSION}

The volume of the eyeball expands rapidly in the first few years of life. By the ages of 4 and 7, the volume of the eyeball is $70 \%$ and $90 \%$ of the adult volume, respectively, and it reaches the adult size in adolescence. Such post-natal development of the eyeball is affected by not only the orbital bone, but also by the size and shape of the surrounding bone. In patients with anophthalmia and microphthalmia or in patients who have received

\section{Fig. 4. Case 1: preoperative and postoperative photographs}

Preoperative anteroposterior view (A), postoperative AP view (B). Preoperative worm's eye view (C), postoperative worm's eye view (D). Comparison of the lower two photograghs shows an increase in malar height.
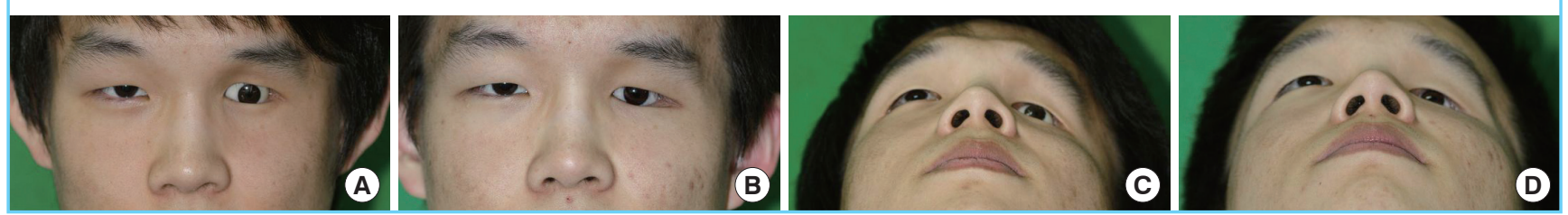

Table 1. The changes in orbital volume and the greatest measured orbital width

\begin{tabular}{|c|c|c|c|c|c|c|c|c|}
\hline Case & $\begin{array}{l}\text { Reconstruct- } \\
\text { ed age (yr) }\end{array}$ & $\begin{array}{c}\text { Enucleated } \\
\text { age (yr) }\end{array}$ & $\begin{array}{l}\text { Unaffected } \\
\text { side }\left(\mathrm{cm}^{3}\right)\end{array}$ & $\begin{array}{l}\text { Affected side } \\
\text { before correc- } \\
\text { tion }\left(\mathrm{cm}^{3}\right)\end{array}$ & $\begin{array}{l}\text { Affected side } \\
\text { after correction } \\
\left(\mathrm{cm}^{3}\right)\end{array}$ & $\begin{array}{c}\text { Increase in } \\
\text { volume } \\
\left(\mathrm{cm}^{3}\right)\end{array}$ & $\begin{array}{l}\text { Orbit width } \\
\text { before surgery } \\
(\mathrm{mm})\end{array}$ & $\begin{array}{l}\text { Orbit width } \\
\text { after surgery } \\
\text { (mm) }\end{array}$ \\
\hline 1 & 19 & 3 & 13.5 & 10.2 & 12.3 & 2.1 & 29 & 33 \\
\hline 2 & 18 & 3 & 14.8 & 10.4 & 12.7 & 2.3 & 30 & 33 \\
\hline 3 & 18 & 2 & 13.9 & 10.2 & 12.4 & 2.2 & 28 & 32 \\
\hline 4 & 20 & 3 & 13.9 & 10.2 & 12.5 & 2.3 & 29 & 32 \\
\hline 5 & 18 & 7 & 14.3 & 10.6 & 12.6 & 2.0 & 29 & 34 \\
\hline Average & 18.6 & 3.6 & 14.1 & 10.3 & 12.5 & 2.2 & 29 & 32.8 \\
\hline
\end{tabular}


enucleation or radiotherapy in infancy, the growth and development of the orbit is not stimulated, leading to local effects such as decreased orbital volume and disrupted development of the surrounding zygomaticomaxillary complex and mandible. The extent of such developmental defects depends on the age at which the eyeball was first absent [5-7].

Retinoblastoma is a disease that is treated by enucleation and irradiation in infancy. Enucleation and irradiation during an important phase of the orbital development and growth inevitably leads to developmental defects in the orbital and facial bones. To minimize such developmental defects, the orbit can be progressively expanded non-surgically by early insertion (as rapidly as the patient can tolerate) of a socket expander such as a silicone expander or hydrophilic expander into the orbital space [8]. However, osteotomy and bone grafting are needed for treatment of patients with anophthalmia or microphthalmia who have missed the orbital expansion time (first diagnosis at 3 to 4 years o ld), or in patients who also present with facial asymmetry of the affected side [2].

Elisevich et al. [9] have reported a surgical technique for osteotomy to correct congenital microphthalmia and anophthalmia, as well as microorbitalism caused by traumatic enucleation or irradiation. This technique involves osteotomy and relocation of the frontal process of the zygoma and the orbital rim to increase the vertical dimension of the orbital aperture.

However, the orbit anatomically consists of parts of the frontal bone superiorly, maxilla inferiorly, ethmoid internally, and zygoma exteriorly, forming a 3-dimensional cone structure. We concluded that the extent of microorbitalism correction by the relocation of the lateral rim alone was limited, and hence we carried out tripod osteotomy to correct the hypoplasia of the neighboring frontal bone, maxilla, and zygoma.

As a result, a postoperative increase in the orbital volume of $2.2 \mathrm{~cm}^{3}$ (21.4\%) was measured with the Aquarius Workstation ver. 4.3.6. The widest width at the start of the orbit as seen in the coronal view of the 3-dimensional facial bone CT was shown to increase from an average of $29 \mathrm{~mm}$ to an average of $32.8 \mathrm{~mm}$ postoperatively. In addition, the malar height was observed to be increased by comparing the preoperative and postoperative photographs, the asymmetry was corrected, so that the aesthetic aspects of patients were improved.

Thus far, tripod osteotomy has been known as an effective technique for correcting facial asymmetry due to congenital abnormalities or malunion following zygoma fractures. In microorbitalism due to retinoblastoma, the neighboring bones show abnormal development. Therefore, previous methods of lateral orbital wall osteotomy only produced limited correction of midfacial asymmetry. On the other hand, tripod oste- otomy relocates the orbital wall by relocating the orbital bonezygoma-maxilla complex, which means that the orbital volume is changed, producing a more aesthetically satisfying outcome of microorbitalism correction.

In this study we improved the microorbitalism secondary to enucleation or irradiation for retinoblastoma of 5 patients, followed by tripod osteotomy and relocation of the orbital bonezygoma-maxilla complex by bicoronal incision. The degree of correction was objectively confirmed by showing an increase in the orbital volume following the procedure. However, the surgical increase in orbital volume in fact induces enophthalmos, which means that the ocular prostheses must be replaced with those of the correct size. Greater improvements would likely be observed in the postoperative photographs if they had been taken with the patients wearing new ocular prostheses instead of the ones they had been using since infancy.

The authors therefore suggest active non-surgical insertion of an expander at the time of enucleation for retinoblastoma, followed by appropriate surgical intervention after development (such as that reported in this study) for the degree of asymmetry of patients.

Relocation of the orbital bone-zygoma-maxilla complex has been used to correct zygomatic changes caused by traumatic malunion or non-traumatic congenital abnormalities such as facial cleft. In this study we applied tripod osteotomy to surgically treat microorbitalism caused by retinoblastoma treatment. We have thus achieved satisfactory outcomes of orbital volume expansion by applying the above technique clinically in patients with retinoblastoma.

\section{REFERENCES}

1. Macdonald AE. Causes of blindness in Canada: an analysis of 24,605 cases registered with the Canadian National Institute for the Blind. Can Med Assoc J 1965;92:264-79.

2. Marchac D, Cophignon J, Achard E, et al. Orbital expansion for anophthalmia and micro-orbitism. Plast Reconstr Surg 1977;59:486-91.

3. Lee KA, Kim JW, Kim YH, et al. Clinical extension of corrective malarplasty with tripod osteotomy. J Craniofac Surg 2012;23:693-5.

4. Jung HJ, Kang SJ, Kim JW, et al. Quantitative analysis of the orbital volume change in isolated zygoma fracture. J Korean Soc Plast Reconstr Surg 2011;38:783-90.

5. Osborne D, Hadden OB, Deeming LW. Orbital growth after childhood enucleation. Am J Ophthalmol 1974;77:756-9.

6. Todd TW, Beecher H, Williams GH, et al. The weight and growth of the human eyeball. Hum Biol 1940;12:1-15. 
7. Eppley BL, Holley S, Sadove AM. Experimental effects of intraorbital tissue expansion on orbitomaxillary growth in anophthalmos. Ann Plast Surg 1993;31:19-26.

8. Morax S, Hurbli T. Orbito-palpebral reconstruction in anophthalmos and severe congenital microphthalmos. Adv
Ophthalmic Plast Reconstr Surg 1992;9:67-80.

9. Elisevich K, Bite U, Colcleugh R. Microorbitalism: a technique for orbital rim expansion. Plast Reconstr Surg 1991; 88:609-12. 